\title{
8 Challenges arising from the use of assistive technologies by people with dementia in home care arrangements
}

\author{
Sarah Palmdorf, Christoph Dockweiler
}

\section{Abstract}

People with dementia living at home are potential users of assistive technologies, as are their informal or professional carers. However, the development of these technologies is oriented more towards what is technically possible as towards the needs of the subsequent users. This is due to the fact that including this group of patients in the development is subject to particular challenges because of their vulnerability and the symptom changes. In addition, weighing the use and the actual application of technology raises both ethical and legal challenges. This implies the formulation and articulation of an informed consent, the emergence of ethical problems depending on the actual system and its application, equal resources and equal opportunities. These ethical problems will be discussed in the following and lead to considerations of the challenges arising from the participation of users and the demands made on technologies and users. So far, the ethical and legal challenges of using the technologies have not been discussed adequately with the user group. There are also no established concepts supporting people with dementia and their relatives when making a decision about using a system, helping them reflect on the possible consequences or finding an alternative that would facilitate self-determined care. Another issue, which has yet to be dealt with, is how decisions made at the onset of the disease should be implemented in the homecare setting during the further course of the illness.

\subsection{Introduction}

In Germany, 1.7 million people suffer from dementia (German Alzheimer's Association 2018). Dementia is an umbrella term identifying a syndrome usually of a chronic nature in which there is a disturbance of multiple higher cortical functions: memory, thinking, orientation, language, judgement and learning (Robinson et al. 2015). The sense of self steadily deteriorates, distancing the people with dementia (PwD) from their former selves and, in turn, their relationship with friends and family (Quinn et al. 2009; Wadham et al. 2016). Further to this, the prevalence of challenging behavior such as anxiety, hallucinations, delusion or disinhibition is high (Savva et al. 2009; van der Linde et al. 2016). Due to the disease, PwD are restricted in their activities of daily living and rely on support from other people. These can be informal carers like family members or professional carers. This potentially leads to a stressful situation for the family and professional carers alike (Gilhooly et al. 2016), but PwD want to stay 
at home as long as possible (von Kutzleben et al. 2012; Wiles et al. 2012) and moving them to a new setting increases confusion and disorientation (Helvik et al. 2018). For this reason, interventions are needed to support $\mathrm{PwD}$ and their relatives in home care. This is where technical systems can be a solution.

In recent years, technical developments have progressed rapidly, whereby the health-related use of communication and information technologies pursues broader targets. These include: a) promoting the efficiency and needs-orientation of prevention and care; b) enabling equal opportunities healthwise; c) strengthening participation and empowerment; d) increasing the economic viability and efficiency of healthcare; e) promoting and disseminating evidence-based healthcare; and f) facilitating specialization in healthcare. PwD and their families are also target groups for technical support systems and these show manifold potential for shaping lives and care. Digital health technologies (DHT) can reduce disease-related risks, e. g. burning down the kitchen or getting lost (Meiland et al. 2017), promote independence (Godwin 2012; Ienca et al. 2016), avoid or postpone residential care (Abbott 2007; Ienca et al. 2016), prolong social inclusion (Abbott 2007) or promote social justice (Godwin 2012) by facilitating access to existing interventions such as telehealth. Research on the use of assistive technology among cognitively impaired users is in its infancy. The current evidence is far from being extensive and the methodological quality of studies has been reported as low (Meiland et al. 2017). Studies with these patient groups are time-consuming and have to fulfill high ethical standards. This impedes the participation of the subsequent user group in the development and research of technical systems.

Because of their illness, PwD have difficulty in using new technologies. This concerns problems with learning, remembering and orientation, e.g. they cannot remember, or only partly, any earlier instructions in connection with technology, have difficulty in understanding verbal instructions and cannot easily recognize audio-visual prompts (Nygård and Starkhammar 2007; Riikonen et al. 2013). Furthermore, they may have other cognitive or physical impairments that influence their use of the technology, e. g. in the case of Parkinson's dementia (Ienca et al. 2016).

All in all, this leads to PwD and their relatives hardly being involved in the development of technical systems. Consequently, systems are developed that do not meet the needs of the later users (Ienca et al. 2016; Meiland et al. 2017). Against this background, ethical implications are found at various levels, which are systemized and discussed in the following. This includes the following aspects: (1) formation and expression of an informed consent; (2) effects and side effects of assistive technologies; and (3) resource access and equal opportunities. Subsequently, ethical problems are made clear by a concrete assistive system. The second part of the chapter deals with the challenges that arise when users are included in product development and evaluation. This results in demands on the technology and the user. At the end of the chapter, the findings are summarized in the form of practical implications for ethical discourse. 


\subsection{Formation and expression of an informed consent}

The user's statement of intent regarding the use or non-use of technical assistance systems presents a challenge for PwD and their relatives. Presumptions that are necessary for setting up and expressing an intention may not be fulfilled because of the existing cognitive impairments. This implicates (1) access to information about the system, (2) the competence to understand the system and (3) reflect the reasons for its use against the background of one's own disease, and (4) the assessment of one's own vulnerability and that of relatives.

Access to information can be problematic at multiple levels. There is still an information deficit for both the users and the professional carers with regard to existing technical systems that could present a solution for the current healthcare problem (Godwin 2012). Access to care-related information is largely dependent on the individual competences of the user groups in the identification and application of the (health-related) technologies. The term "competence" refers back to the concepts of health literacy research. This relates to the knowledge, motivation and competences people need in order to find, understand, assess and apply the relevant health information in its various forms; they can then make judgments and decisions in everyday life relating to healthcare and health promotion, disease management and prevention, which maintain or improve their quality of life throughout their lives (Zamora et al. 2015). Here eHealth literacy can be regarded as a field of health literacy that refers specifically to the use and acquisition of information and knowledge within online-based health communication; this, however, calls for extended competence in the application and understanding of information and communication technologies (Neter and Brainin 2012). This includes computer and media competences (the knowledge and ability to find and use technologies and various online-media), information competences (knowing how online information is organized), literal competences (the knowledge and ability to understand online information) but also scientific competences (the basic knowledge about the significance and classification of scientific findings) (Norman and Skinner 2006). Up to now, there are no methods for a standardized assessment of eHealth literacy of PwD, nor are there any concepts for promoting this.

People with dementia and their relatives might have problems with the autonomous search of information, especially on the internet (Kim 2015). Currently, this generation of PwD has few biographic experiences on which they can rely regarding this topic. This will change in the following generations. Furthermore, it is not clear how the information, especially that regarding the use of more complex systems, should be prepared so that it is understandable despite cognitive limitations. This includes information concerning data protection for the acquisition, processing, transmission and storage of data, whereby the question here is to what extent data acquisition on humans is automated. If health-related (and other relevant) data are collected without the user being actively involved (e.g. automatically via cameras), then safety is 
objectively increased, although in the end the desired emancipation and self-determination is not achieved. On the contrary, competences are no longer supported and care is often completely beyond one's own control (Siep 2007). It is also unclear how to ensure that the information relating to the handling of the data has been understood.

Reflecting whether the PwD has the competence to form a will about the use of technical systems is also problematic, especially when changing symptoms are taken into account. In addition, the verbalization of expressions of intent may be limited due to communicative restrictions caused by dementia. When considering the reasons for use, the dependence on support from relatives or professional carers must be borne in mind, since both are also part of the decision-making process on the use of assistive technologies. When weighing the various interests, the question arises to what extent a free choice for or against the use of a system actually exists, if the supporting person or organization has its own interest in using the technologies or when there is a dependency on the supporting system that increases as the illness progresses (Niemeijer et al. 2010). For instance, the PwD might decide to use a global positioning system (GPS) because he wants to relieve his relatives who feel easier if the PwD has the help of a GPS. Or an outpatient care service might use a form of communication technology to expedite internal processes without which they could not offer their services. This is followed by the question as to what effects the non-utilization of a technology would have on the care situation and whether this would result in poorer care, so that there is de facto no freedom of choice about using the technology or the person at least feels compelled to use it. This might be the case if clinical monitoring can only be realized digitally (e. g. by means of a video consultation) because the PwD is restricted in his mobility or lives too far away.

Although it is difficult to set up and express an informed consent, the main target remains: to maintain and promote the autonomy of the PwD (Nuffield Council on Bioethics 2009; Zimmermann-Acklin 2005); they are afraid of losing their independency and control of their lives or that their wishes will not be respected. However, studies have shown that PwD are indeed able to decide about using a technological system and that to generally reject the ability to make decisions is not acceptable (Godwin 2012).

\subsection{Effects and side effects of assistive technologies}

Compiling the effects and side effects of using assistive technologies according to the principle "do-no-harm" is impeded by the changing dementia symptoms and the high prevalence of challenging behaviors. Interpreting behavior depends on each individual situation, since behavior can be influenced by internal and external triggers, which are not necessarily connected to the use of the technology (Kales et al. 2018; Sachweh 2019). This makes it difficult to explain a behavior with regard to the accep- 
tance of the technology or its impact on PwD. In addition, the disease can make early verbal articulation difficult (Szatloczki et al. 2015), which hampers the assessment of the effects and side effects of technologies for this group of people. It is particularly problematic if the PwD lives alone and side effects only become noticeable during this time, e. g. due to diurnal disorientation, and the PwD develops a fear of the technology because lights or acoustic signals are not recognized as part of the system. Side effects may therefore not be noticed by relatives or professional carers. Other side effects may be more subtle and do not result in strong outward-directed behavior. For instance, a living area that is equipped with sensors, cameras and mobile devices no longer provides the feeling of "being at home" that had been the original reason for being cared for in the own home. Another side effect might lie in the PwD becoming too dependent on the technology, whereby the possible impact on the self-image and on the handling of the disease has not yet been investigated. Further side effects may result from the possible dependency of the PwD on the technology. Up to now, there have been no studies dealing with the possible effects to the self-image of the PwD or with how he copes with the disease, nor have any long-term studies been conducted that investigate the effect of assistive technologies on the course of the disease. This makes it difficult to assess the effects, effective relationships and side effects on PwD who use assistive technologies.

\subsubsection{Resource access and equal opportunities}

A further ethical area of conflict arises in the interaction of social, health and digital inequalities and the resulting question of resource accessibility for different population groups. The patient possibly has to pay for the technology as well as its maintenance on his own. Depending on the cognitive and motoric abilities of the PwD, support from the family is required (or is deemed to be required individually) in order to ensure the handling of technological health solutions. The lack of these resources can lead to unequal opportunities for the affected persons. Health services to improve the care situation should be accessible to all patients and at all times, regardless of the state of health or location. In a predominantly rural area with a low concentration of specialist physicians, the possibility for consulting a specialist about information and communication technologies during the course of the treatment is an important aspect of healthcare. Due to the networking of various types of health personal on different levels or sectors, digital health technology can contribute towards ensuring care safety and quality in the sense of services to the public even in areas with little medical and nursing infrastructure (AGENON 2009).

Inequalities of access to DHT can be ascribed to diverse living conditions at various levels. Assuming that technical, individual and social resources are subject to a socio-economic gradient, this can first lead to discrimination against people with lower socio-economic status in such a way that they are less able to master health 
technologies and therefore benefit less from them. The same applies to a second dimension of inequality with regard to socio-demographical characteristics (e.g. age, gender). This reveals disparities with regard to the technology-related self-efficacy, the perceived assessment of potentials and risks of the health-related use of technology and, ultimately, its use (Wewer et al. 2013). A third dimension, which can grow to be an inequality with regard to DHT, is the culture, i. e. the entirety of the values, norms, attitudes and beliefs of a person from a specific cultural area. Direct interrelations between culture and the accessibility of technology exist in the form of language barriers or (even) culturally shaped technology orientation. Indirect influences from the cultural environment are to be assumed against the background of individual values, e.g. with regard to the desired relationship between doctor and patient or the general attitude or affinity to technology (Kummer 2010). A fourth dimension of inequality can be found in the geographical influences within the phenomenon of the digital divide. While the use of DHT lifts geographical healthcare barriers, an adequate coverage of the basic digital technologies (e. g. broadband connections, mobile data networks) is, nevertheless, a prerequisite (Westermeier 2014).

If assistive technologies were to be used everywhere in the care of $\mathrm{PwD}$, the aforementioned influences would have to be questioned with regard to discrimination against a group of people. This applies especially to the access to resources, since up to now none of the technologies is partly or entirely financed by the health insurance in general; and since the disease potentially leads to a financial burden (Kim and Schulz 2008), people with low financial means would not be able to use the technologies. This is the actual healthcare situation at the moment, since assistive technologies can still only be purchased through private financial means.

A further risk of inequality exists for PwD who have a migration background. Even in the early stages of the disease, the affected people can lose the ability to communicate in their second language, which at the same time is considered shameful (Forbat 2003). Technologies that require the use of the second language might exclude this group of people. If this problem were taken into consideration during the development of assistive technologies, it would provide a chance of overcoming language barriers.

In the following, the ethical problems concerning specific technology will be presented and discussed.

\subsubsection{Ethical problems in using global positioning systems (GPS)}

Taking the use of GPS as an example, it becomes clear what ethical problems exist with the individual use of a concrete system. The individual application is the deciding factor whether the GPS is used for the PwD's deception in promoting freedom and autonomy or as a restraint. The deception of the PwD might be the fact that the PwD is unaware of the system being used; for instance, he is not told that the "watch" can be 
used as a tracking device or that it's hidden in his clothes. The relatives might choose to deceive the PwD if they are afraid the use might otherwise be rejected. The family members would then be in a dilemma: if from their point of view the PwD needs but rejects the use of a GPS, the use is ethically justifiable because the PwD would forget he was using the technology (Godwin 2012; Niemeijer et al. 2010).

The concrete use and the respective system are also decisive for whether the system is used in the sense of maintaining and promoting space for movement or as a measure restricting freedom. Significant here is the question of when an alarm is activated and what reactions occur as a result. For example, a system might give an alarm if the PwD leaves a certain area, or stays longer than usual in one particular place, or leaves the building. The relative could then wait and see because he knows that the person usually leaves the house for half an hour. Or he accompanies the PwD back into the house immediately because he is of the opinion that the PwD would get lost outside. The respective reaction to the alarm and the alarm itself are the key to whether the system is used for maintaining or restricting freedom of movement. In addition and with regard to the restriction of freedom, consideration must be given to other measures the relative might use as a result of the pressure to act and prevent the PwD from leaving the house - locking the front door or administering sedatives, perhaps. Assessing the alternative measures complicates the ethical risk assessment for the use of a system. The evaluation of the technology by the relatives is also important in this context; generally, they are more likely to estimate technologies that promote autonomy as being ethically acceptable. To what extent the use is ethically correct has to be judged according to the possible consequences. If the various values have to be weighed up against each other, then safety usually has the highest priority (Godwin 2012). Furthermore, due to the challenges with cognitive abilities the relatives do not generally trust the PwD to make a decision e. g. with regard to using a GPS (Landau and Werner 2012). This means that the evaluation of the possible use on the part of the PwD and their relatives can therefore vary. As a consequence, conflicts can arise that can be an additional strain on the care situation. Up to now, there is no established procedure in the practice that can support the PwD and their relatives in estimating the use of a certain system.

\subsubsection{Challenges in user orientation and participation}

One of the difficulties in the development and evaluation of technical solutions for improving care in the case of a dementia illness lies in realizing the demand and needs of the user groups and in adapting existing technologies or developing new ones in order to fulfill these demands.

In order to promote user orientation in research and development it will in the future be crucial not only to explain the attitudes, perceptions and needs within the framework of health services research but also to integrate these productively in the 
development stages of healthcare innovations. Such fields of intervention particularly require an inter- and transdisciplinary discourse between science, politics, practice and business that starts as early as possible in the planning and development of innovations. This includes innovative forms of cooperation between practice and science, the co-production of knowledge as well as the participation of relevant user groups. For this purpose, methods of participatory healthcare research appear to be of particular significance.

There are various approaches in participative research that follow the principle "knowledge for action" and not only "knowledge for understanding" (Cornwall 2008), whereby the interventions should be designed participatively, have an assured quality and be structured in a way that is related to the world in which we live (setting-based) (Rosenbrock 2010); additionally, the practice-relevant people and/ or groups should take part as active co-designers and/or decision makers (depending on the degree of participation) (Bergold 2007; Compagna and Kohlbacher 2015). However, the interpretation of "participation" on which this approach is based is very divergent (Unger 2014). Among other things, it seems expedient to consider participation as a continuum within research processes. Depending on its nature, it moves between the extremes of mere information giving to the participants, via listening to and taking in of attitudes and opinions (e. g. via surveys) up to co-determination and partial decision-making power (Wright et al. 2010). According to this interpretation, the degree of participation is to be measured, among other things, by the extent to which someone has influence on the different decision-making processes within research projects.

Participative processes in research are thus directed towards the planning and implementation of a cognitive process together with those people and/or groups whose social (health-relevant) actions and their life and work experiences are the subject of investigation. The term "participation" emphasizes the active attendance and the involvement in the research; it characterizes the relationship between the researchers and the participants in respect of both sides: on the one side, the participants' cooperation in the research process, on the other side the involvement of the researchers in the processes and social contexts of the settings being explored (Bergold and Thomas 2012). This means for research practice that research-relevant interest in knowledge develops from the interaction of two (at first sight possibly incongruent) perspectives - science and praxis. The research process thus becomes (at best) a win-win for both sides: the "practice" (e. g. physicians, nurses, patients, people from the technology development field), which has long since become an object of knowledge in its relevant fields of action, contributes its individual knowledge, skills and perspectives to the related problems of life in science itself (Bergold and Thomas 2012). The objectives of the participative designing of research processes are the promotion of an individual and collective learning process with the relevant people and groups in each field of research as well as the consideration of the variety of opinions, attitudes and interests in order to better understand the societal processes 
and problems and to design strategies with more practical relevance. Furthermore, participation in application-related research should help to avoid conflicts arising (e. g. through developing intervention strategies that are not tailored to the needs in the practice) (Blackstock et al. 2007). The required interlacing of perspectives in science and practice in participative research designing cannot be created simply by the decision to participate. In fact, it is a methodically challenging approach (Östlund et al. 2015); it develops successively in the actual research process via the encounters, interactions and understanding processes, possibly breaking with traditional roles in research, and thus placing complex demands on research processes and all those involved. The range and definition of problems does not primarily take place in the context of the scientific interest in knowledge, but according to social needs. A process which, according to its importance for the needs-related design, implementation and use of assistive technologies, is still inadequately represented today.

\subsection{Demands on the technologies and users}

On the societal level, there are clear demands regarding the use of technical systems. They should maintain privacy, promote social participation, and should ensure safety for the person with dementia and their data. The technology does not aim to replace human attention or promote isolation. The system should not initiate any action or decision without the user's consent. The responsibilities and liability issues should be clear and the explanations should be in understandable language. Furthermore, the costs (of the system) should be ecologically comprehensible and transparent. The user must have the opportunity to try the product out before a decision is made (Hansen et al. 2017). On the other hand, general requirements are expected of the technology user who should be able to act and decide autonomously and should understand the technology. The user should agree to use the technology, and conflicts between user groups should be communicated open-mindedly and proactively in order to find a solution. The user should be able to switch either the whole technology or individual parts of it off or on (Hansen et al. 2017). These requirements should ensure that the user can influence the technology so that it can be applied according to his needs. Fulfilling these requirements might be a challenge for PwD in the homecare setting and ethical issues might arise. In addition, the developers themselves and professional health service providers (i. e. who use data to optimize their processes) have a responsibility to meet these requirements. Coping with these challenges can result in a burden for the PwD and their relatives. 


\subsection{Practical implications of ethical discourse}

As a result of technical developments, the repertoire of intervention options is expanding so rapidly that discussions about their social and health-related consequences are often only conducted afterwards. At the same time, such fields of research and development require an inter- and trans-disciplinary discourse between science, politics and practice that commences as early as possible in the planning and development of innovative care settings and within which the perspectives and ethical conflicts of the various user groups can be identified and taken into account.

The prerequisites needed to use assistive technologies are manifold. A distinction must be made between requirements that are: a) in relation to the usage context; $b$ ) in support of the product: and c) located directly with the users. This could include for example creating easier framework conditions (e.g. legal security, transparence regarding data flow and quality, remuneration within healthcare, technical infrastructure, establishing responsibilities), designing the technology (e.g. usability, technological interoperability due to uniform standards) and the implementation of the innovations in healthcare to meet the demands and needs as well as prerequisites of the users to provide a far-reaching perspective on the conditions of use. This also includes the analysis of effectiveness and efficacy of assistive technologies. In addition, the question must be asked as to how the relationship between man and technology is configured and what relevance user orientation has in the development and introduction of assistive technologies.

The more specifically an intervention meets the demands and needs of a target group, the more comprehensively and transparently framework conditions are created to facilitate action and the more potential burdens are reduced. The clearer the benefits of an intervention are presented and communicated, the sooner the specific reservations and fears of a target group are identified during the planning of digitally supported care settings and incorporated into an ethical, trans-disciplinary discourse. In result, the more rigorously these are addressed within communication and participation processes, then the more likely does a successful process of technology use become.

Besides the broad repertoire of research methods for the explication of the user perspective on innovative supply technologies, the question of the methodology of participation is just as crucial. By enabling participation, the necessary mutual learning process of the various actors can be promoted further. The existing diversity of opinions and interests can also be taken better into account in research and development, and potential conflicts and obstacles in the implementation of care concepts can be identified in advance and reduced accordingly. Participation thus represents a central step towards ensuring that the healthcare needs and requirements of different population and patient groups are met, and ultimately also towards clarifying and solving the ethical implications of the technologies. 


\section{References}

Abbott, Chris. 2007. Defining assistive technologies - a discussion. Journal of Assistive Technologies. https://doi.org/10.1108/17549450200700002.

AGENON. 2009. Entwicklung der Telemedizin im Land Brandenburg aus versorgungsinhaltlicher Sicht. Berlin. https://masgf.brandenburg.de/media/lbm1.a.1336.de/telemedizin.pdf. Accessed 26 May 2019.

Bergold, Jarg. 2007. Participatory strategies in community psychology research - a short survey. In Poland welcomes community psychology: Proceedings from the 6th European Conference on Community Psychology, ed. A. Bokszczanin, 57-66. Opole: Opole University.

Bergold, Jarg, and Stefan Thomas. 2012. Participatory Research Methods: A Methodological Approach in Motion. Forum: Qualitative Social Research 13: 30.

Blackstock, K. L., G. J. Kelly, and B. L. Horsey. 2007. Developing and applying a framework to evaluate participatory research for sustainability. Ecological Economics 60: 726-42.

Compagna, D., and Kohlbacher, F. 2015. The limits of participatory technology development: the case of service robots in care facilities for older people. Technological forecasting and social change. https://doi.org/10.1016/j.techfore.2014.07.012

Cornwall, A. 2008. Unpacking 'Participation': models, meanings and practices. Community Development Journal. https://doi.org/10.1093/cdj/bsn010.

Forbat, Liz. 2003. Concepts and understandings of dementia by 'gatekeepers' and minority ethnic 'service users'. Journal of health psychology. https://doi.org/10.1177/13591053030085013.

German Alzheimer's Association. 2018. Die Häufigkeit von Demenzerkrankungen. Informationblatt 1. www.deutsche-alzheimer.de/. Accessed 21.04.2019.

Gilhooly, K. J., M. L. M. Gilhooly, M. P. Sullivan, A. McIntyre, L. Wilson, E. Harding, R. Woodbridge, and S. Crutch. 2016. A meta-review of stress, coping and interventions in dementia and dementia caregiving. BMC geriatrics. https://doi.org/10.1186/s12877-016-0280-8.

Godwin, Beatrice. 2012. The ethical evaluation of assistive technology for practitioners: a checklist arising from a participatory study with people with dementia, family and professionals. Journal of Assistive Technologies. https://doi.org/10.1108/17549451211234975.

Hansen, Thomas, Melissa Henne, Ralf Müterthies and Mihaela Neculau. 2017. Ethische Leitlinien für das Projekt KogniHome - die mitdenkende Wohnung. https://www.kogni-home.de/sites/ kogni-home.de/files/2017-06-29\%20KogniHome_Ethische\%20Leitlinien_Layout.pdf. Accessed 1 June 2019.

Helvik, Anne-Sofie, Geir Selbæk, Jūratė Šaltytė Benth, Irene Røen, and Sverre Bergh. 2018. The course of neuropsychiatric symptoms in nursing home residents from admission to 30-month follow-up. PloS one. https://doi.org/10.1371/journal.pone.0206147.

lenca, Marcello, Fabrice Jotterand, Constantin Vică, and Bernice Elger. 2016. Social and assistive robotics in dementia care: ethical recommendations for research and practice. International Journal of Social Robotics. https://doi.org/10.1007/s12369-016-0366-7.

Kales, Helen C., Laura N. Gitlin, Barbara Stanislawski, H. Myra Kim, Katherine Marx, Molly Turnwald, Claire Chiang, and Constantine G. Lyketsos. 2018. Effect of the WeCareAdvisor ${ }^{\mathrm{TM}}$ on family caregiver outcomes in dementia: a pilot randomized controlled trial. BMC geriatrics. https://doi. org/10.1186/s12877-018-0801-8.

Kim, Heejung. 2015. Understanding internet use among dementia caregivers: Results of secondary data analysis Using the US Caregiver Survey Data. Interactive journal of medical research. https://doi.org/10.2196/ijmr.3127.

Kim, Youngmee, and Richard Schulz. 2008. Family caregivers' strains: comparative analysis of cancer caregiving with dementia, diabetes, and frail elderly caregiving. Journal of aging and health. https://doi.org/10.1177/0898264308317533. 
Kummer, Tyge-F. 2010. Akzeptanz von Ambient Intelligence in Krankenhäusern. Ein Ländervergleich zwischen Deutschland und Australien am Beispiel der Medikationsunterstützung. Lohmar: EUL.

Landau, Ruth, and Shirli Werner. 2012. Ethical aspects of using GPS for tracking people with dementia: recommendations for practice. International psychogeriatrics. https://doi.org/10.1017/ S1041610211001888.

Meiland, Franka, Anthea Innes, Gail Mountain, Louise Robinson, Henriëtte van der Roest, J. Antonio García-Casal et al. 2017. Technologies to support community-dwelling persons with dementia: A position paper on issues regarding development, usability, effectiveness and cost-effectiveness, deployment, and ethics. JMIR rehabilitation and assistive technologies. https://doi. org/10.2196/rehab.6376.

Neter, Efrat, and Esther Brainin. 2012. eHealth literacy: extending the digital divide to the realm of health information. Journal of medical Internet research. https://doi.org/10.2196/jmir.1619.

Niemeijer, Alistair R., Brenda J. M. Frederiks, Ingrid I. Riphagen, Johan Legemaate, Jan A. Eefsting, and Cees M. P. M. Hertogh. 2010. Ethical and practical concerns of surveillance technologies in residential care for people with dementia or intellectual disabilities: an overview of the literature. International psychogeriatrics. https://doi.org/10.1017/S1041610210000037.

Norman, Cameron D., and Harvey A. Skinner. 2006. eHealth Literacy: Essential skills for consumer health in a networked world. Journal of medical Internet research. https://doi.org/10.2196/ jmir.8.2.e9.

Nuffield Council on Bioethics. 2009. Dementia. Ethical issues. London: Nuffield Council on Bioethics.

Nygård, L., and S. Starkhammar. 2007. The use of everyday technology by people with dementia living alone: mapping out the difficulties. Aging \& mental health. https://doi. org $/ 10.1080 / 13607860600844168$.

Östlund, B., Olander, E., Jonsson, O., and Frennert, S. 2015. STS-inspired design to meet the challenges of modern aging. Welfare technology as a tool to promote user driven innovations or another way to keep older users hostage. Technological Forecasting and Social Change. https:// doi.org/10.1016/j.techfore.2014.04.012

Quinn, Catherine, Linda Clare, and Bob Woods. 2009. The impact of the quality of relationship on the experiences and wellbeing of caregivers of people with dementia: a systematic review. Aging \& mental health. https://doi.org/10.1080/13607860802459799.

Riikonen, Merja, Eija Paavilainen, and Hannu Salo. 2013. Factors supporting the use of technology in daily life of home-living people with dementia. Technology and Disability. https://doi. org/10.3233/TAD-130393.

Robinson, Louise, Eugene Tang, and John-Paul Taylor. 2015. Dementia: timely diagnosis and early intervention. BMJ (Clinical research ed.). https://doi.org/10.1136/bmj.h3029.

Rosenbrock, R. 2010. Partizipative Qualitätsentwicklung - um was es geht. In Partizipative Qualitätsentwicklung in der Gesundheitsförderung und Prävention, ed. Michael T. Wright, 9-12. Bern: Hans Huber.

Sachweh, Svenja. 2019. Spurenlesen im Sprachdschungel. Kommunikation und Verständigung mit demenzkranken Menschen. Bern: Hogrefe Verlag.

Savva, George M., Julia Zaccai, Fiona E. Matthews, Julie E. Davidson, Ian McKeith, and Carol Brayne. 2009. Prevalence, correlates and course of behavioural and psychological symptoms of dementia in the population. The British journal of psychiatry : the journal of mental science. https://doi.org/10.1192/bjp.bp.108.049619.

Siep, L. 2007. Ethik und Telemedizin. In Telemedizin - Innovationen für ein effizientes Gesundheitsmanagement, ed. AnyCare, 65-75. Stuttgart: Thieme.

Szatloczki, Greta, Ildiko Hoffmann, Veronika Vincze, Janos Kalman, and Magdolna Pakaski. 2015. Speaking in Alzheimer's disease, is that an early sign? Importance of changes in language 
abilities in Alzheimer's disease. Frontiers in Aging Neuroscience. https://doi.org/10.3389/ fnagi.2015.00195.

Unger, Hella von. 2014. Partizipative Forschung. Einführung in die Forschungspraxis. Wiesbaden: Springer VS.

van der Linde, Rianne M., Tom Dening, Blossom C. M. Stephan, A. Matthew Prina, Elizabeth Evans, and Carol Brayne. 2016. Longitudinal course of behavioural and psychological symptoms of dementia: systematic review. The British journal of psychiatry: the journal of mental science. https://doi.org/10.1192/bjp.bp.114.148403.

von Kutzleben, Milena, Wolfgang Schmid, Margareta Halek, Bernhard Holle, and Sabine Bartholomeyczik. 2012. Community-dwelling persons with dementia: what do they need? What do they demand? What do they do? A systematic review on the subjective experiences of persons with dementia. Aging \& mental health. https://doi.org/10.1080/13607863.2011.614594.

Wadham, Olivia, Jane Simpson, Jonathan Rust, and Craig Murray. 2016. Couples' shared experiences of dementia: a meta-synthesis of the impact upon relationships and couplehood. Aging \& mental health. https://doi.org/10.1080/13607863.2015.1023769.

Westermeier, Andreas. 2014. Der deutsche Telekommunikationsmarkt im europäischen und internationalen Vergleich. Wirtschaftsdienst. https://doi.org/10.1007/s10273-014-1730-6.

Wewer, A., C. Dockweiler, R. Beckers, and C. Hornberg. 2013. Alter und Geschlecht als wesentliche Einflussfaktoren für die Akzeptanz telemedizinischer Verfahren bei Patientinnen und Patienten. In eHealth 2013 - Informations- und Kommunikationstechnologien im Gesundheitswesen, ed. Frank Duesberg, 216-21. Solingen: Medical Future.

Wiles, Janine L., Annette Leibing, Nancy Guberman, Jeanne Reeve, and Ruth E. S. Allen. 2012. The meaning of ,aging in place“ to older people. The Gerontologist. https://doi.org/10.1093/geront/ gnr098.

Wright, Michael T., Hella von Unger, and M. Block. 2010. Partizipation der Zielgruppe in der Gesundheitsförderung und Prävention. In Partizipative Qualitätsentwicklung in der Gesundheitsförderung und Prävention, ed. Michael T. Wright, 35-52. Bern: Hans Huber.

Zamora, Pablo, Paulo Pinheiro, Orkan Okan, Eva-Maria Bitzer, Susanne Jordan, Uwe H. Bittlingmayer, Fabian Kessl, Albert Lenz, Jürgen Wasem, Maren A. Jochimsen, and Ullrich Bauer. 2015. „Health Literacy“ im Kindes- und Jugendalter. Prävention und Gesundheitsförderung. https:// doi.org/10.1007/s11553-015-0492-3.

Zimmermann-Acklin, Markus. 2005. Telemedizin in der Praxis - ethische Fragen. Tagung zur Telemedizin von Ta-Swiss. www.ta-swiss.ch. Accessed 21 April 2019. 
